\title{
A study of the factors affecting mobile money penetration rates in the West African Economic and Monetary Union (WAEMU) compared with East Africa
}

\author{
Sionfou Seydou Coulibaly ${ }^{*}$ (1)
}

\author{
*Correspondence: \\ coulsionfseyd@yahoo.fr \\ Department of Economics \\ and Management, University \\ Félix Houphouët Boigny \\ of Abidjan, Cocody, PO \\ Box: 01 BP 974 Abidjan 01, \\ Abidjan, Côte d'Ivoire
}

\begin{abstract}
According to the 2017 Global Financial Inclusion (Global Findex) database, the average penetration rate of mobile money accounts in East Africa is higher than that of the WAEMU. This study attempts to understand the factors driving the adoption and the use of mobile financial services in the WAEMU compared to East Africa. To achieve this, micro-level data from the 2017 Global Findex database are used to perform probit and multinomial logit estimations. The findings reveal that the same determinants influence the adoption and use of mobile money accounts across the populations of both groups of countries, specifically those related to the least vulnerable social categories (i.e., males, older, more educated, richer and part of the workforce). Therefore, in comparison to East Africa, the delay in the penetration of mobile money accounts observed in the WAEMU may be attributed to insufficient policies for increasing the awareness of the benefits of mobile financial services. The study recommends that governments in WAEMU countries promote the use of mobile money accounts among the working-age population (adults aged between 25 and 64) through the improvement of individual income level, and the introduction of incentives into the education system to encourage their population to attain higher levels of education.
\end{abstract}

Keywords: Financial inclusion, Mobile money, Probit, Multinomial logit, East Africa, WAEMU

JEL Classification: C33, C34, C35, G21, R10

\section{Introduction}

In the 1970s McKinnon (1973) and Shaw (1973) raised arguments against policies of financial repression. In that, they developed a theoretical framework that helped to explain growth-inducing effects of financial liberalization in contrast to financial repression. Qualified as direct government intervention that alters the equilibrium reached in the financial sector, financial repression usually aims at providing cheap loans to companies and governments, reducing their burden of repayments by lowering returns to savers below the rate that otherwise would prevail. Applied in numerous forms such author(s) and the source, provide a link to the Creative Commons licence, and indicate if changes were made. The images or other third party material in this article are included in the article's Creative Commons licence, unless indicated otherwise in a credit line to the material. If material is not included in the article's Creative Commons licence and your intended use is not permitted by statutory regulation or exceeds the permitted use, you will need to obtain permission directly from the copyright holder. To view a copy of this licence, visit http:// creativecommons.org/licenses/by/4.0/. 
as ceilings on interest rates, directed credits to certain industries, or constraints on the composition of bank portfolios, financial repression is typically accompanied by additional restrictions on financial activity (Jafarov et al. 2020).

After the discovery and the condemnation of the policy of financial repression two decades ago, another hindrance to financial intermediation was detected in the 1990s: the inability of various segments of the world population to access formal banking services. This inadequacy is termed as "financial exclusion" (Leyshon and Thrift 1993).

According to Aron (2017), the exclusion of many people from financial services in the world is due to the high and prohibitive costs of maintaining sufficient numbers of bank branches in rural areas and the incapacity of the poor to maintain the requisite minimum balance and pay the regular bank charges for standard bank accounts.

Nevertheless, due to the contribution of financial inclusion ${ }^{1}$ in terms of fighting against poverty and attaining greater and more inclusive growth, the latter has become, since the beginning of the second decade of the twenty-first century, one of the pillars of the international development agenda (Banque de France 2014). Consequently, most world economies began integrating actions geared towards reducing financial exclusion in their development strategies.

In 2011, the total adult population in the world was estimated at 5 billion; 2.5 billion of these adults were holders of bank accounts while the other 2.5 billion were unbanked. By 2014, the world's adult population had increased to 5.2 billion, with 3.2 billion adults having bank accounts and 2 billion being unbanked. Between 2014 and 2017, 515 million adults worldwide opened an account at a financial institution or through a mobile money provider leaving about 1.7 billion adults unbanked in 2017. Thus, in 2017, 69 percent adults had bank accounts, up from 62 percent in 2014 and 51 percent in 2011 (Demirgüç-Kunt et al. 2018). According to Demirgüç-Kunt et al. (2015), the increase in the level of financial inclusion worldwide has been fueled by growth in account penetration rates in developing countries which includes mobile money accounts. This helped to rapidly expand access to financial services in Sub-Saharan Africa.

In Sub-Saharan Africa, after the implementation of the M-PESA ${ }^{2}$ platform in Kenya, in 2007, mobile money banking became an alternative for spreading financial services beyond the limits of bank branches. In this dynamic, to improve the level of access to finance in the WAEMU, the central bank of its member states $\left(\mathrm{CBWAS}^{3}\right)$, initiated a vast program of financial inclusion from 1999, which from 2009 included mobile money. According to data from the 2017 World Bank's Global Findex database, eight years from its inception in 2009, mobile money adoption in the WAEMU slightly exceeded one-quarter of the adult population with an average rate of almost $29 \%$. By comparing the 2017 average penetration rate $^{4}$ of mobile money accounts in the WAEMU and the one of the member states of East Africa ${ }^{5}$ (the region where the mobile money was

\footnotetext{
${ }^{1}$ Financial Inclusion refers to the process that allows individuals and firms to access basic financial services (funds deposits and transfers, payments, savings, credit, insurance) provided by formal financial institutions.

2 The acronym M-PESA is defined as M for "mobile" and PESA for "money" in Kiswahili. It is the local appellation given to mobile financial services which were first implemented in Kenya in 2007 by the Safaricom mobile phone company.

3 Central Bank of West African States.

4 Calculated from the Global Findex database.

5 East African countries here are Ethiopia, Kenya, Madagascar, Malawi, Mauritius, Mozambique, Rwanda, Tanzania, Uganda, Zambia and Zimbabwe. These countries are part of East African countries in the classification made by the United Nations Statistics Division (UNSD) and are those in which the Global Findex data were collected in 2017.
} 
first launched, precisely in Kenya, and spread to all its member states), a slight gap is observed. While the mobile money account penetration rate in 2017 was, on average, almost 29\% in the WAEMU, it was, on average, around 33\% in the group of East African countries.

Although there is only a slight gap between the WAEMU and East African countries in terms of mobile money account penetration rates (a gap of almost 4 percentage points), a wide gap is observed between the countries in the respective regions with the highest rates of money account penetration. Within the WAEMU, the highest mobile money account penetration rate was almost 34\% (registered in Côte d'Ivoire), while within East African countries this rate was almost 73\% (registered in Kenya). This difference raises questions on the characteristics of the users of mobile money in the WAEMU compared to East African countries' users.

To help increase the use of mobile money in the WAEMU to the extent observed in East Africa, one has to consider the factors that drive the adoption and use of mobile money in the former compared to the latter. Thus, the following question arises: Is the difference in the rate of penetration of mobile money services in the WAEMU compared with that of East African countries due to differences in the characteristics of certain segments of the population?

The objective of this study is to identify the individual characteristics which determine the ownership and use of mobile money accounts in the WAEMU in comparison to East African countries. To achieve this objective, two assumptions are empirically tested. The first suggests that greater ownership of mobile money accounts is associated with the profile of the least vulnerable social categories in the WAEMU. The second suggests that greater use of mobile money accounts is associated with the profile of the least vulnerable social categories in the WAEMU.

For the empirical verification of the assumptions, the Global Findex database was used to perform probit and multinomial logit estimations. The results showed that, in both East Africa and WAEMU countries, the ownership and use of mobile money accounts are higher among the least vulnerable social categories (men, older, richer, more educated people and those in the workforce).

It is important to note that in recent years, several studies have addressed the problematics of the determinants of mobile money use, but none of them have attempted to identify these determinants by comparing two regions or countries. This study, therefore, brings an empirical contribution to economic literature by detecting the factors that influence the adoption and use of mobile money in one region compared to another with higher penetration rate of mobile money accounts.

The rest of the study is organized as follows: Sect. 2 is a review of literature on mobile money. Section 3 presents some stylized facts on the penetration of mobile money in the WAEMU as compared to East Africa. Section 4 details the data and the variables. Section 5 presents the empirical methodology. Section "Results and discussion" presents the results and discussion. Section "Conclusion" gives the conclusion and policy recommendations. 


\section{Literature review}

Economic literature analyzing the benefits of financial inclusion in improving the living conditions of people and developing an economy has increased. Most of these analyses highlight the factors influencing the adoption of formal banking as well as those of mobile money. A review of some factors related to the adoption and use of mobile money is presented in this section.

Due to its versatility, the mobile telephone is being used as a tool that simplifies access to financial services and makes it easy for a growing number of the unbanked to access them. The capacity of mobile financial services to constitute an instrument that allows for the integration of a higher number of the unbanked in the financial system is the subject of several articles in literature. Most of these studies are preoccupied with the question of the adoption and use of mobile money. According to Aron (2017 and 2018), mobile money is a recent financial innovation giving financial transaction services via a mobile phone, including to the unbanked global poor.

Several studies have focused on examining the socio-economic factors that influence the adoption of mobile money services. In this regard, in studying the socio-economic aspect of mobile money, Murendo et al. (2018) identified the role of social networks in the adoption of mobile money in Uganda. They used survey data from 477 rural households and a probit model. The results of the study showed that training within social networks has contributed to the spread of information on mobile money and has improved its adoption. Compared to poor households, non-poor households were more dependent on social networks in terms of obtaining information on mobile money. In addition to this, they assumed that the adoption of mobile money was likely to be enhanced if promotion programs reached more social networks. In the same vein, Senou et al. (2019) examined the driving factors of mobile money adoption and the policies that could be implemented to alleviate the bottlenecks of the low digital financial inclusion in the WAEMU. Using both country and individual-level data from the World Bank database, they conducted a cluster analysis and thereafter a logistic regression to investigate both the macroeconomic and microeconomic driving factors of mobile money adoption. They found that country characteristics including literacy rate, labor force, mobile infrastructure, and banking infrastructure in terms of number of ATMs (Automated Teller Machines) per 100,000 people were the main macroeconomic determinants of mobile money adoption. In addition, being young, male, educated, relatively richer and even banked increased the likelihood of adopting mobile money in the WAEMU. Similarly, Afawubo et al. (2020) investigated the determinants of mobile money adoption and whether its use helped households in Togo to be resilient to predictable and unpredictable life events. Using ordered logit and sequential logit models, their results showed that in the adoption process, households benefit from weak ties of social groups such as religious groups and informal savings groups for the adoption of mobile money. They equally found that being a client of banks or microfinance institutions acted as a powerful channel from one step to another in the process. Besides, their findings revealed that households that use mobile money seem to be more resilient to climatic shocks such as drought, irregular rain, soil degradation, erosion and fertility reduction and to non-climatic shocks such as high prices of agricultural inputs that affect households' assets. However, the picture was more contrasted when the individuals were classified 
as disadvantaged groups such as rural people, women and less educated and people with low incomes.

Based on the fact that the use of mobile financial services remains low among the poor even though they are available in areas where formal financial institutions are unavailable, Lema (2017) investigated the factors that influenced the adoption of mobile financial services among the unbanked population of Chamwino District in Tanzania. Using Structural Equation Modeling, it was revealed in the study that perceived usefulness, perceived cost and social influence had a significant effect on the adoption of mobile financial services. Similarly, based on the interest of the people in the peripheral regions of Africa (where there are no conventional banking services at all) to adopt mobile money technology, Akinyemi and Mushunje (2020) explored the determinants of mobile money adoption. The authors used data from Research ICT Africa (RIA) for the study; it was analyzed with a two-part model, where the first part involved the adoption of mobile money and the second part involved how much money was sent or received using mobile money. It was revealed in the study that age, years of education, unemployment, and ownership of bank accounts explain both the adoption and the amount of money sent using mobile money technology. Conversely, age, bank account ownership, and net monthly income determine both the adoption of mobile money and the amount of money received using mobile money technology. Despite the benefits provided by mobile money services for trade such as payment of bills, reduced cost and time for transactions, increased savings options, sales, and convenience-their adoption and use by traders in Uganda remains low. This prompted Malinga and Maiga (2019) to explore the challenges traders face in using and adopting mobile money services in Uganda. To do this, the authors used survey data collected through a self-administrated questionnaire from 394 respondents and a conceptual model for mobile money adoption based on the Unified Theory of Acceptance and Use of Technology (UTAUT). The findings of their analysis revealed that performance expectancy, social influences, and sensitization constructs significantly influence traders' behavioral intention to adopt mobile money services for trade. On the other hand, security and effort expectancy did not significantly influence traders' behavioral intention to adopt mobile money services. Furthermore, the findings revealed that facilitating conditions influenced the behavior of traders to use mobile money services for trade transactions. Going by the assertion that mobile money is a mobile-based service, which provides access to low-cost financial services for people excluded from the banking system, Peruta (2018) investigated whether the adoption of mobile money services was highest in countries where access to formal banking services was lowest. Using a wide macroeconomic approach to the adoption of mobile money in 2011 and 2014, based on the alternative strategy of cluster analysis, the author exploited the new technology diffusion frameworks to evaluate dissimilarity among groups of countries in emerging and developing countries with similar levels of adoption of mobile money. The analytical results supported the predictions in the technology diffusion literature and nuanced the potential of mobile money as a tool to counter banking exclusion.

Basing themselves on the fact that mobile money is expanding rapidly across the African continent with the potential to raise financial inclusiveness, Bair and Tritah (2019), investigated the impact of the introduction of mobile money in 2010 on the amount and frequency of funds sent and received among Malagasy households. The authors used 
a selection model combined with an instrumental variable approach to deal with the selective participation into the transfer market and the endogeneity of mobile money adoption. They showed that access to mobile money had triggered more financial transactions between households at both the extensive (number of potential users) and intensive margin (level of funds). The findings of their study suggested that transactions costs were important and acted as barriers to entry for the poor.

\section{Stylized facts on the WAEMU compared to East Africa}

The operationalization of mobile money services within the WAEMU from 2009 followed a project that promoted electronic currency formulated a few years earlier under a CBWAS regulatory framework promulgated in 2006. However, until 2014 or five years after the introduction of mobile money banking, as shown in Fig. 1, a large disparity remained between WAEMU countries in terms of penetration of mobile money accounts. This disparity is highlighted through a variation ranging from $1 \%$ in Togo to almost 24\% in Côte d'Ivoire. In the year 2014, in all the WAEMU countries, the highest percentage of adults with access to a mobile account was almost $24 \%$ (registered in Côte d'Ivoire); in other words, less than a quarter of the adults (aged 15 and above). Three years later, in 2017, the highest percentage of adults with access to mobile money banking crossed the line of $30 \%$ in three of the WAEMU countries: it was around 33\% in Burkina Faso, 34\% in Côte d'Ivoire and 32\% in Senegal. By comparing the state of the evolution of the users of mobile money accounts in Burkina Faso and Niger that had the same initial mobile money account penetration rates in 2014, the statistics in Fig. 1 show that from 2014 to 2017, the mobile money account penetration rate in Burkina Faso increased from almost 3\% to almost 33\%; while in Niger it increased from almost $3 \%$ to almost 9\%. Furthermore, looking at the statistics of the year 2017, it is noticed that, apart from Benin and Niger whose mobile money account penetration rates were below $20 \%$, the rates of the other WAEMU member states were above $20 \%$ (Fig. 1). In the disparity of the penetration rates of mobile money accounts observed from 2014 to 2017

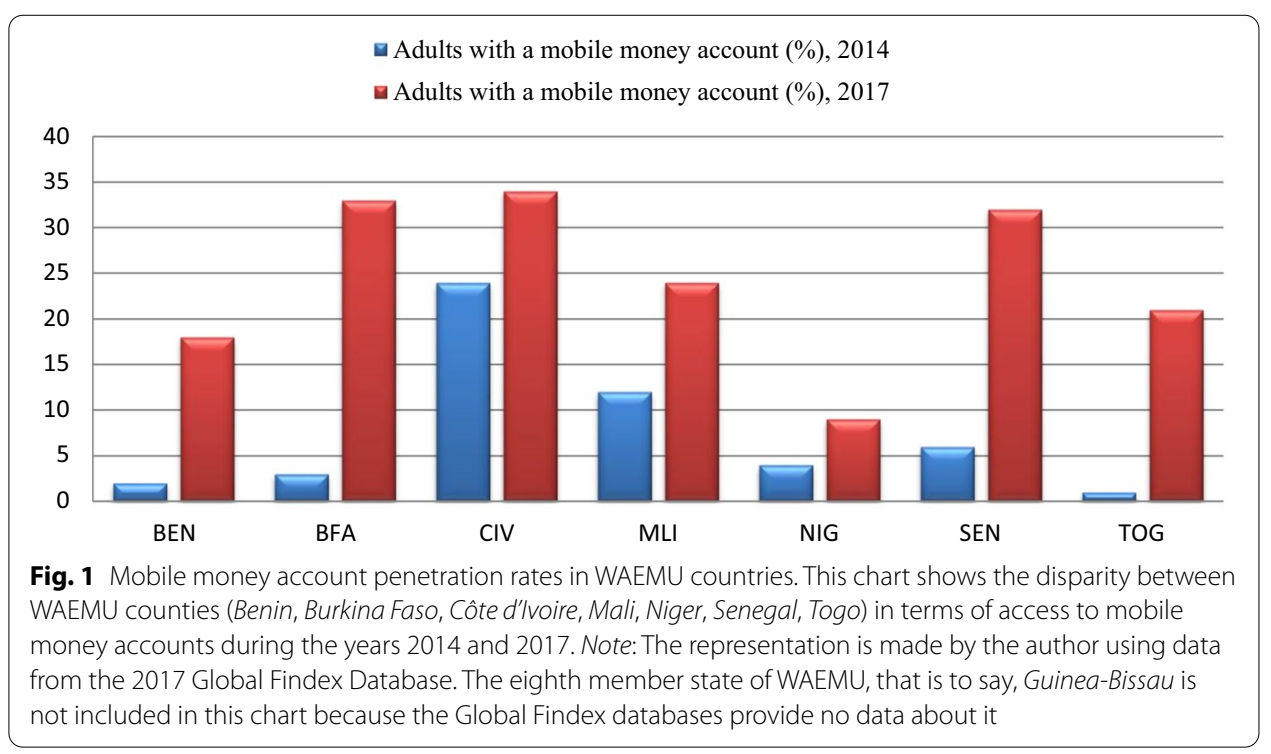


in WAEMU, there were increases ranging from over 15 percentage points to almost 30 percentage points in four countries (Benin, Burkina Faso, Togo and Senegal), while there were increases from almost 5 percentage points to under 15 percentage points in three countries (Côte d'Ivoire, Mali, and Niger). It was observed that among the three countries of the WAEMU with weak increases, two had the highest increase of over 10 percentage points in 2014, that is, Côte d'Ivoire and Mali. Thus, in the WAEMU, the countries that had the highest mobile money account penetration rates of over $10 \%$ in 2014 made less progress over the period 2014-2017 than those which had rates below $10 \%$ in 2014.

Like WAEMU countries, East African countries recorded significant growth in their mobile money account penetration rates over the period 2014-2017 (Fig. 2). While Kenya, Malawi, Rwanda, Uganda, Zambia and Zimbabwe recorded increases going from over 10 to almost 27 percentage points, Madagascar, Mauritius and Tanzania registered increases ranging from almost 5 to less than 10 percentage points, while growth in Ethiopia was recorded at under 0.3 percentage points. Thus, in East African countries, the countries (excluding Tanzania) that had the highest mobile money account penetration rates of over 10\% in 2014 made more progress from 2014 to 2017 than those (excluding Malawi) which had rates below $10 \%$ in 2014 .

Overall, most of the East African countries that experienced higher rates of mobile money account penetration since the implementation of mobile money banking continue to make progress more rapidly than those of WAEMU.

The weakness in the adoption of mobile money accounts in WAEMU is established when the statistics on mobile money account penetration rates of its member states are compared with those of some reference East African countries which adopted the mobile money earlier or in the same year as the WAEMU countries. These reference countries are Kenya, the pioneer of mobile money banking, which adopted mobile money in 2007,

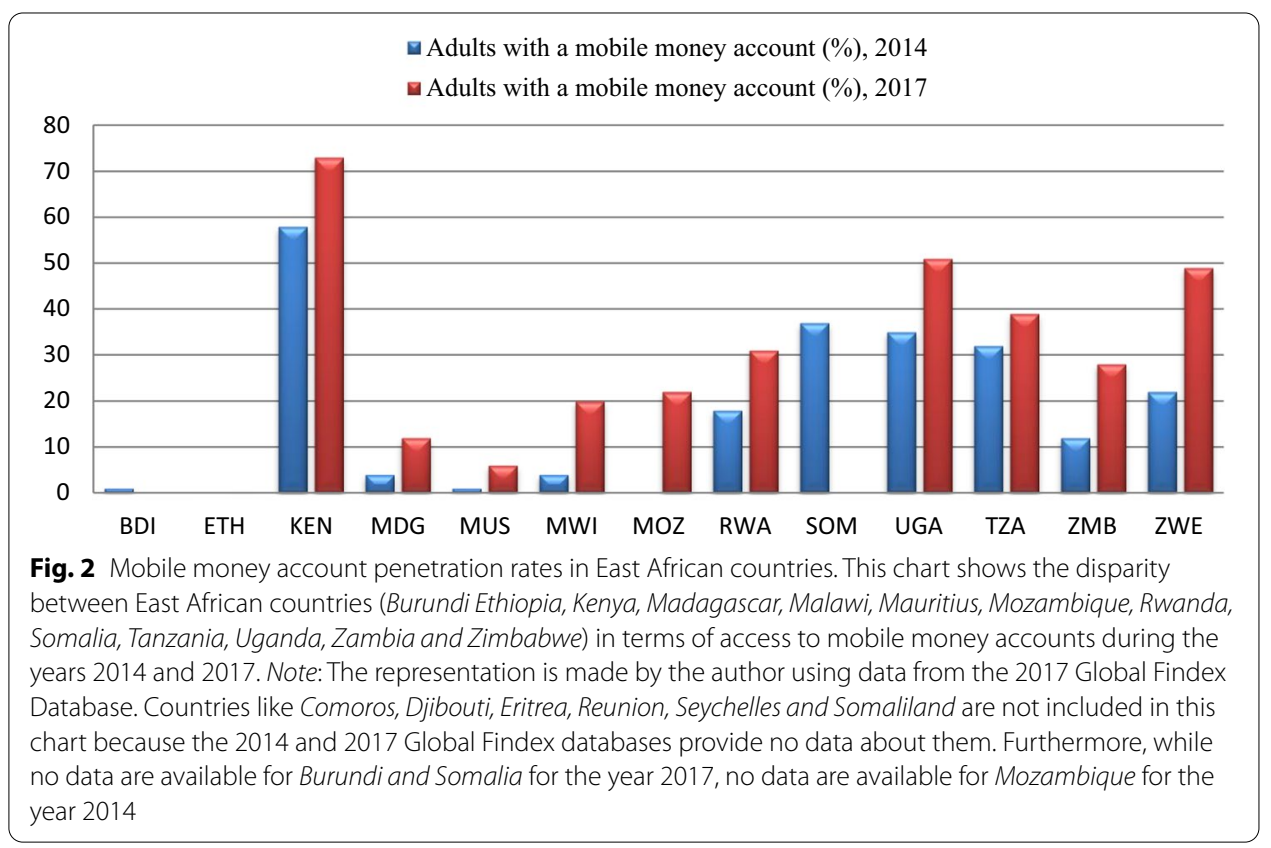


Tanzania, which adopted it in 2008, and Uganda and Somalia, which adopted it in 2009. According to the statistics in Figs. 1 and2, a large gap is observed between WAEMU countries and the reference countries that recorded rapid growth in the use of mobile money services. In 2014, while no WAEMU country reached a mobile money account penetration rate of a quarter of adults (i.e., $25 \%$ ), the penetration rate of adults with a mobile money account in Kenya was higher than 50\%; and in Somalia, Tanzania, and Uganda, more than a quarter of adults became mobile money account holders.

In terms of the pace of adopting mobile money, a large disparity is observed between WAEMU countries and East African countries. From the statistics in Fig. 1, it is observed that the WAEMU country with the highest (almost 24\%) mobile money account penetration rate in 2014 (i.e., Côte d'Ivoire) had the highest (almost 34\%) mobile money account penetration rate in 2017, which corresponds to an increase of almost 10 percentage points. However, in Fig. 2, it is observed that the East African country with the highest (almost 58\%) mobile money account penetration rate in 2014 (i.e., Kenya) had the highest (almost 73\%) mobile money account penetration rate in 2017, which corresponds to an increase of almost 15 percentage points. The gaps between the two countries were around 34 percentage points in 2014 and around 39 percentage points in 2017.

Given the wide gap between the two top countries in each of the regions, that is, the WAEMU and East Africa, one may infer that different factors motivate the adoption of mobile money in their member states.

\section{Data and financial inclusion indicators}

This section presents the source of the data used to perform estimations aimed at identifying the drivers of financial inclusion through mobile money. The survey methodology used to obtain these data is also presented. The financial inclusion variables considered in this study are the ownership of a mobile money account and the use of the services provided through these accounts. This study considers sending remittances, receiving remittances, and paying public utility bills as the services provided through mobile money accounts.

\section{Data source}

This study uses individual-level data from the 2017 World Bank's Global Findex database for 7 WAEMU and 11 East African countries.

The sample of WAEMU countries includes Benin, Burkina Faso, Côte d'Ivoire, Mali, Niger, Senegal, and Togo. The eighth country of WAEMU Guinea-Bissau, is not included in this sample because no data are available about it in the 2017 Global Findex database.

The sample of East African countries includes Ethiopia, Kenya, Madagascar, Malawi, Mauritius, Mozambique, Rwanda, Tanzania, Uganda, Zambia, and Zimbabwe. The remaining countries of this region, that is, Burundi, Comoros, Djibouti, Eritrea, Reunion, Seychelles, Somalia, and Somaliland are not included in the sample because no data are available about them in the 2017 Global Findex database. The East African countries in this study are those included in the classification of the United Nations Statistics Division (see UNSD 2021). 


\section{Data survey methodology and description}

The 2017 Global Findex database is based on interviews with almost 150,000 people in 144 economies using randomly selected, nationally representative samples. The survey was carried out over the 2017 calendar year by Gallup, Inc., as part of its Gallup World Poll, which since 2005 has annually conducted surveys of approximately 1000 people in each of more than 160 economies and in over 150 languages, using randomly selected, nationally representative samples. The target population is the entire civilian, non-institutionalized population aged 15 and above. The Global Findex database provides many indicators on financial inclusion, enabling assessment of the extent of account penetration, the use of financial services, the purpose and motivation behind the use, and the alternatives to formal finance, etc. It also provides microlevel information - gender, age, income, and education - used in our estimations.

The understanding of financial inclusion through mobile money banking is based on five measures of financial inclusion drawn from the Global Findex database.

The first measure of financial inclusion through mobile money is about the adoption of mobile money, that is, the ownership of a mobile money account, and which refers to the percentage of respondents who personally used a mobile money service in the past 12 months.

Regarding the use of mobile money services, we used a categorical variable built from the three measures of mobile money services provided in the 2017 Global Findex database: "Sending remittances", "Receiving remittances" and "Paying utility bills". This categorical variable includes four modalities:

1. Modality 0 equals no use of mobile money services in line with the above measures;

2. Modality 1 equals using one of the above mobile money services;

3. Modality 2 equals using two of the above mobile money services;

4. Modality 3 equals using all three mobile money services mentioned above.

"Sending remittances" refers to respondents who personally sent any of their money in the past 12 months to a relative or friend living in a different area of their country using a mobile money account. "Receiving remittances" refers to respondents who reported personally receiving money in the past 12 months from a relative or friend living in a different area of their country via a mobile money account. "Paying utility bills" refers to respondents who reported personally making regular payments for water, electricity, or trash collection in the past 12 months directly using a mobile money account.

The statistics in Appendix Table 3 show that in East African countries, on average, close to $33 \%$ of adults aged 15 and above hold a mobile money account, while in WAEMU, on average, around $29 \%$ of these adults hold a mobile money account. Therefore, with a gap of almost 4 percentage points, mobile money is slightly less adopted in WAEMU countries than in East African countries.

However, when considering the use of mobile money accounts, we observe that, on average, close to $36 \%$ of adults aged 15 and above in WAEMU countries use their accounts to perform only one mobile money service, while in East African countries, on average, almost $28 \%$ of these adults perform one mobile money service only. 
Regarding the use of two mobile money services, on average, almost $19 \%$ and $20 \%$ of adults did so in WAEMU countries and in East African countries, respectively.

When we consider the use of the three mobile money services, the statistics indicate that only $4 \%$ of adults in the WAEMU regularly used these three services, while in East Africa, we observed that around 9\% of the adults used them.

\section{Empirical methodology}

This section first presents the basic model of the study which was then used to perform estimations.

\section{The model of the study}

Based on the objective of the study, the econometric model considered is:

$$
y_{i j}=\alpha+\text { BFemale }_{i j}+\lambda \text { Age }_{i j}+\theta \text { Age }_{i j}^{2}+\gamma \text { Income }_{i j}+\rho \text { Education }_{i j}+\varphi \text { Laborforce }_{i j}+\varepsilon_{i j},
$$

where $y_{i j}$ is the dependent variable that represents each of the financial inclusion measures (the ownership of an account and the usage of an account) for individual $i$ in country $j$. The explanatory variables are composed of individual level characteristics. $\beta, \lambda, \theta, \gamma, \rho$ and $\varphi$ are parameters to be estimated and $\varepsilon_{i j}$ is an error term normally distributed with zero mean and a variance that is equal to 1 .

Female is a dummy variable which equals 1 if the individual is a woman (Female) and zero if otherwise.

Age is the respondent's age in years and $A g e^{2}$ is the respondent's age in years, squared to control for a possible nonlinear relation between age and financial inclusion. As stated by Allen et al. (2016), age squared is included in the equation to capture the fact that the use of accounts first increases and then declines with age.

Regarding income, we created five dummy variables in line with the categories provided in the Global Findex database (poorest 20\%, second 20\%, middle 20\%, fourth $20 \%$ and richest 20\%). Each of these dummy variables is equal to 1 if income is in the first income quintile and 0 if elsewise. In the regressions, the quintile poorest $20 \%$ is the omitted dummy variable.

Concerning education, we used three dummy variables based on groupings from the Global Findex database (Secondary education, Primary education, and Tertiary education). Primary education is a dummy that is equal to 1 if the respondent had up to 8 years of education and 0 if otherwise. Secondary education is a dummy that is equal to 1 if the respondent completed secondary education and some education beyond secondary education (9-15 years of education) and 0 if elsewise. Tertiary education is a dummy that is equal to 1 if the respondent completed four years of education beyond high school and/or received a 4-year college degree and 0 if elsewise. The omitted dummy variable is tertiary education.

Concerning labor force, two dummy variables were used: in workforce and out of workforce. In workforce is a dummy that is equal to 1 if the respondent is in the workforce and 0 if otherwise. Out of workforce is a dummy that is equal to 1 if the 
respondent is out of the workforce and 0 if otherwise. The variable out of workforce is the omitted dummy.

The statistics in Appendix Table 4 give the proportions of the characteristics considered in this study. In this perspective, it is observed that female represents a proportion of $41 \%$ in the sample of WAEMU countries, while this proportion is $58 \%$ in the sample of East Africa countries. In the sample of WAEMU countries, we have the proportions of $61 \%, 36 \%$ and $3 \%$ for respondents with the primary education level, the secondary education level and the tertiary education level, respectively, while these proportions are 55\%, 42\% and 3\%, respectively, in the sample of East African countries. The income quintile variable indicates that, in the sample of WAEMU countries, $16 \%, 17 \%, 18 \%, 21 \%$ and $28 \%$ of respondents are in the poorest quintile, the second quintile, the middle quintile, the fourth quintile and the richest quintile, respectively, while these proportions are $17 \%, 18 \%, 18 \%, 21 \%$ and $26 \%$, respectively, in the sample of East African countries. The labor force variable shows the proportions of $32 \%$ and $68 \%$ for respondents out of workforce and in workforce, respectively, in the sample of WAEMU countries. But, these proportions are $25 \%$ and $75 \%$ for respondents out of workforce and in workforce, respectively, in the sample of East African countries. Next to these proportions, the average age of respondents is 33 years in the sample of WAEMU countries, while it is 35 years in the sample of East African countries.

Table 5 in appendix presents the measurement of explanatory variables, while Table 6 shows the descriptive statistics on the penetration of mobile money accounts by each of them.

In Table 6 it is observed that the proportions of men as compared to women are close to $68 \%$ versus $32 \%$ among the respondents who reported having a mobile money account in the WAEMU countries, while these proportions were around $51 \%$ versus $49 \%$ in East African countries. These statistics show that there is a greater gap between men and women in terms of usage of mobile money banking in the WAEMU than in East African countries. While the rate of women holding a mobile money account is reaching that of men in East African countries, in the WAEMU, women are still lagging behind men in terms of mobile money account ownership.

The proportions of mobile money account holders in the WAEMU with at least secondary and higher education levels as compared to those with at least a primary education level are almost $43 \%$ versus 57\%, respectively; while these proportions are almost $31 \%$ versus $69 \%$, respectively, among respondents in East African countries.

The proportion of mobile money account holders in the working-age group (i.e., aged between 25 and 64) as compared to younger individuals (i.e., aged between 15 and 24) is almost $69 \%$ versus $29 \%$, in the WAEMU; while these proportions are close to $66 \%$ and $31 \%$ respectively, in East African countries. In both samples, it is clear that younger people are less interested in using mobile money banking than the working-age group.

The proportions of mobile money account holders within the two highest income quintiles (Richest 20\% and Fourth 20\%) as compared to those within the lowest income quintiles (Middle 20\%, Second $20 \%$ and Poorest $20 \%$ ) are almost $59 \%$ versus $41 \%$, respectively, in the WAEMU, while these proportions are around $59 \%$ versus $41 \%$, respectively, in East African countries. Thus, the tendency to own a mobile money account in 
both the WAEMU and East African countries is the same for both poorest and richest individuals.

The proportions of individuals in the workforce with a mobile money account as compared to those out of the workforce are almost $78 \%$ versus $22 \%$, respectively, in the WAEMU, while these proportions are around $81 \%$ versus 19\%, respectively, in East African countries. Thus, in both the WAEMU and East African countries, individuals in the workforce are more likely than those out of the workforce to own a mobile money account.

In all, we observe that the use of only one mobile money service (sending remittances only or receiving remittances only or paying utility bills only) is higher in the WAEMU than in East Africa. But, in East Africa, there are more people using more than one service than there are in the WAEMU. From the analysis of individual characteristics of mobile money service users, it emerged that in both WAEMU and East African countries, men, people who are richer, older, more educated and in the workforce are more likely to own mobile money accounts.

\section{The models for estimations}

We propose in this section the different models used to identify the determinants of financial inclusion measures through mobile money. In this dynamic, as far as the decision to own an account or not follows a binary choice, a simple probit model was used to determine the drivers of the ownership of a mobile money account in the WAEMU as compared to East African countries. However, regarding the use of mobile money services associated with mobile money accounts, as we had more than two alternatives of using these mobile money services, a multinomial model was used to perform the estimations: the multinomial logit.

\section{The choice of the probit model}

According to Gujarati (2011), binary response regression models can be estimated by the logit or probit models. These two models generally give similar results. The main difference between the two models is that the error term in the logit model follows a logistic distribution, while the error term in the probit model follows a normal distribution. The logistic distribution has slightly fatter tails; recall that the variance of a logistically distributed random variable is about $\pi^{2} / 3$, whereas that of a (standard) normally distributed variable is 1 . But in practice, there is no compelling reason to choose one over the other.

\section{The choice of the multinomial logit model}

From the multinomial distribution literature, the multiple-choice models are a generalization of the models of binary choice in which the explained variable is no longer binary but multinomial or polytomous. In this perspective, the individual chooses among more than two choices, making the choice that provides the greatest utility (Greene 2012). However, regarding the nature of the explained variable, there are two broad types of multinomial choice sets: unordered choices and ordered choices, and we can distinguish between unordered multinomial regression models and ordered multinomial regression models. 
The main characteristic of models of ordered qualitative responses is that all the options depend upon a unique indicative function. This makes sense when the responses have a natural order, but not otherwise. A different type of model is obviously needed to tackle unordered responses. The simplest method is that of using a multinomial logit model, which is mostly used in applied studies. A method that is relatively close to this model, and known as the conditional logit model, is also widely used. In this study, given that the choices of the different alternatives of mobile payment services associated with the use of a mobile money account are unordered, it followed that we should perform multinomial logit estimations. However, the stringent assumption of multinomial and conditional logit models is that outcome categories for the model have the property of independence of irrelevant alternatives (IIA). Stated simply, this assumption requires that the inclusion or exclusion of categories does not affect the relative risks associated with the regressors in the remaining categories.

So, before using the multinomial logit, an important thing to do is to perform IIA test to check if the IIA assumption is violated. Under the IIA assumption, we would expect no systematic change in the coefficients if one alternative is excluded from the model. The results of the test of Hausman and MacFadden (1984) confirmed that the IIA assumption was not violated in this study (see Appendix Tables 7 and 8). Then, the multinomial logit model was used to perform estimations.

\section{Determinants of the ownership and use of mobile money accounts}

\section{The ownership of mobile money accounts}

Table 1 shows the estimations of the examination of the link between individual characteristics and the measure of the ownership of a mobile money account. In this table, the probability of holding a mobile money account in both the WAEMU and the group of benchmark countries from East Africa is considered. Each cell in columns in the Table shows the coefficients of the estimations, the standard errors (in parentheses and are clustered at the country level) and the marginal effects (in italics) that capture how the probability of the account ownership changes with a change in the value of a regressor, keeping the other variables constant (Allen et al. 2016).

Columns (1) and (2) show the estimations of the probability of owning a mobile money account, respectively in WAEMU and the group of East African countries. Due to the cross-sectional nature of the data, the estimated coefficients can only be interpreted as significant correlations between individual characteristics and the measure of financial inclusion (the ownership of the mobile money account) and not as causal relationships (Allen et al. 2016).

The estimated likelihood ratios (LR) chi-square of 1034.9380 and 3798.867, respectively, in the context of WAEMU and East African countries with p-values of 0.0001 confirm that our model is statistically significant, that is, it fits significantly better than a model with no predictors.

The gender variable showed a negative significant association with the ownership of mobile money accounts both in WAEMU and East African reference countries. These results indicated that being a woman does not significantly influence the ownership of a mobile money account in the two samples. For example, the marginal effects show that the probability of holding a mobile money account is almost 4 
Table 1 Determinants of the ownership of a mobile money account: probit estimations

\begin{tabular}{|c|c|c|}
\hline \multirow[t]{2}{*}{ Dependent variable } & \multicolumn{2}{|c|}{ Account's ownership } \\
\hline & WAEMU countries & East African countries \\
\hline Explanatory variables & Column 1 & Column 2 \\
\hline \multirow[t]{3}{*}{ Female } & $-0.1734^{* *}$ & $-0.1555^{* * *}$ \\
\hline & -0.041 & -0.0367 \\
\hline & -0.0517 & -0.0403 \\
\hline \multirow[t]{3}{*}{ Age } & $0.0309^{* * *}$ & $0.0307^{* * *}$ \\
\hline & -0.0049 & -0.0083 \\
\hline & 0.0092 & 0.008 \\
\hline \multirow[t]{3}{*}{ Age squared } & $-0.0004^{* * *}$ & $-0.0004^{* * *}$ \\
\hline & -0.0001 & -0.0001 \\
\hline & -0.0001 & -0.0001 \\
\hline \multirow[t]{3}{*}{ Primary education } & $-0.8131^{* * *}$ & $-0.7584^{* * *}$ \\
\hline & -0.0652 & -0.0601 \\
\hline & -0.2417 & -0.197 \\
\hline \multirow[t]{3}{*}{ Secondary education } & $-0.2819^{* * *}$ & $-0.2190^{* * *}$ \\
\hline & -0.065 & -0.0594 \\
\hline & -0.0838 & -0.0569 \\
\hline \multirow[t]{3}{*}{ Income: poorest 20\% } & $-0.4075^{* * *}$ & $-0.7293^{* * *}$ \\
\hline & -0.0761 & -0.0558 \\
\hline & -0.1212 & -0.1894 \\
\hline \multirow[t]{3}{*}{ Income: second 20\% } & $-0.1905^{* * *}$ & $-0.5061^{* * *}$ \\
\hline & -0.0448 & -0.0772 \\
\hline & -0.0566 & -0.1315 \\
\hline \multirow[t]{3}{*}{ Income: middle 20\% } & $-0.1948^{* * *}$ & $-0.4564^{* * *}$ \\
\hline & -0.0508 & -0.0352 \\
\hline & -0.0579 & -0.1185 \\
\hline \multirow[t]{3}{*}{ Income: fourth $20 \%$} & $-0.1610^{* * *}$ & $-0.3023^{* * *}$ \\
\hline & -0.052 & -0.041 \\
\hline & -0.0479 & -0.0785 \\
\hline \multirow[t]{3}{*}{ In workforce } & $0.4181^{* * *}$ & $0.3439^{* * *}$ \\
\hline & -0.0356 & -0.049 \\
\hline & 0.1243 & 0.0893 \\
\hline \multirow[t]{2}{*}{ Constant } & $-0.8504^{* * *}$ & 0.196 \\
\hline & -0.1347 & -0.1316 \\
\hline Observations & 6888 & 10,945 \\
\hline LR chi2: & 1034.94 & 3798.87 \\
\hline Prob >chi2: & 0 & 0 \\
\hline Pseudo R2 & 0.1250 & 0.2737 \\
\hline Log pseudo likelihood & -3623.40 & -5039.63 \\
\hline Country fixed effects & YES & YES \\
\hline
\end{tabular}

The different columns give the estimation results of a regression of the indicator of financial inclusion (the ownership of a mobile money account) on a set of individual characteristics and country fixed effects. ${ }^{* *},{ }^{* *}$ and ${ }^{*}$ denote significance threshold at the $1 \%, 5 \%$, and $10 \%$, respectively. In each cell are presented in the first position the coefficient of the estimation, then in the second position the standard errors that are in parentheses and clustered at the country level, and in the third position the marginal effects that are in italics. The WAEMU countries' sample includes Benin, Burkina Faso, Côte d'Ivoire, Mali, Niger, Senegal and Togo. The East African countries' sample includes Ethiopia, Kenya, Madagascar, Malawi, Mauritius, Mozambique, Rwanda, Tanzania, Uganda, Zambia and Zimbabwe 
percentage points lower for women than for men both in WAEMU and East African reference countries.

Furthermore, we observed that the probability of owning a mobile money account increases with age both in WAEMU and East African reference countries. The probability of owning a mobile money account increases as individuals progress from primary education level to secondary education level. Thus, the likelihood of having a mobile money account is higher for more educated people than for less educated people in both regions. For example, the marginal effects showed that the probability of holding a mobile money account was almost 8 percentage points higher for more educated people than for the less educated ones in WAEMU countries, while this probability was around 6 percentage points in East African reference countries.

Regarding the income quintile indicator, it was observed that the probability of holding a mobile money account increases when moving from lowest income quintile to richest income quintile in both regions. It showed that richer people were more likely to own a mobile money account in both WAEMU and East African reference countries. For example, the marginal effects showed that the likelihood of holding a mobile money account was almost 5 percentage points higher for richer people than for poorer ones in the WAEMU, while this likelihood was around 8 percentage points higher in East African reference countries.

Concerning the workforce variable, the results showed that the probability of owning a mobile money account increases for an individual in the workforce than for an individual out of the workforce in both samples. The marginal effects showed that the probability of holding a mobile money account was around 12 percentage points higher for an individual in the workforce than for his counterpart out of the workforce in the WAEMU, while this probability is only almost 9 percentage points higher for an individual in the workforce than for his counterpart out of the workforce in East African reference countries.

To sum it up, the probability of holding an account in the WAEMU is higher among men, people that are older, more educated and richer and in the workforce. Furthermore, these results are in line with the findings of Zins and Weill (2016) who found the same drivers for mobile money banking as well as for formal banking in the context of Africa.

\section{The use of mobile money accounts: multinomial logit regressions}

\section{Results}

Table 2 shows the results of regressing individual characteristics on the financial inclusion indicators related to mobile money banking, i.e., sending remittances, receiving remittances, paying utility bills. The financial inclusion indicators are grouped into four alternatives which are: (1) using none of the indicated mobile money services, (2) using one mobile money service only, (3) using two mobile money services, (4) using all three mobile money services indicated. The results as presented in Table 2 show the factors influencing the various structures of decisions related to the use of a mobile money account in WAEMU and East African countries. The results of the estimations were obtained using the multinomial logit model. In the process of regressing the multinomial logit, the alternative with the highest frequency was considered as "base category," 


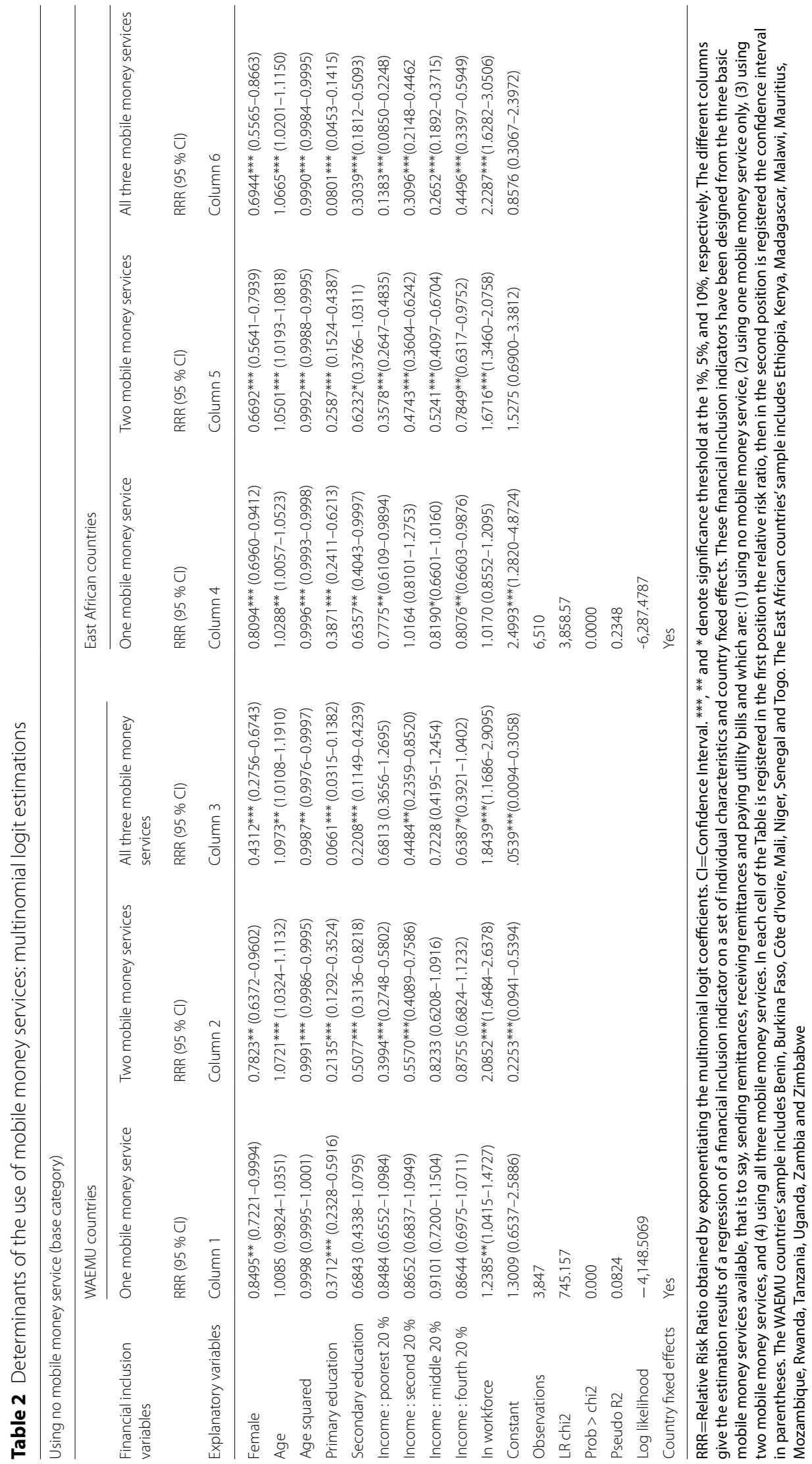


which is "use no mobile money service." The results are discussed using RRR (the Relative Risk Ratio) which explains the likelihood of choosing one alternative over the other (reference category). The RRR is obtained by exponentiating the multinomial logit coefficients. The RRR of a coefficient indicates how the risk of the outcome falling in the comparison group compared to the risk of the outcome falling in the referent group changes with the variable in question. An RRR $>1$ indicates that the risk of the outcome falling in the comparison group relative to the risk of the outcome falling in the referent group increases as the variable increases. In other words, the outcome is more likely to be in the comparison group. An $R R R<1$ indicates that the risk of the outcome falling in the comparison group relative to the risk of the outcome falling in the referent group decreases as the variable increases. In general, if the $R R R<1$, the outcome is more likely to be in the referent group.

The estimated likelihood ratios (LR) chi-square of 745.1570 and 3858.5700, respectively, in the context of WAEMU and East African countries with p-values of 0.0001 confirm that our model is statistically significant, that is, it fits significantly better than a model with no predictors.

In column (1) of Table 2, we observe that in the context of the WAEMU that the relative risk of using only one mobile money service (either sending remittances or receiving remittances or paying utility bills) compared to using no mobile money service decreases for women compared to men by a factor of 0.8495 ( $95 \% \mathrm{CI}=0.7221-0.9994)$, for individuals in primary education level as compared to those in higher education levels by a factor of $0.3712(95 \% \mathrm{CI}=0.2328-0.5916)$; while it increases for individuals in the workforce by a factor of 1.2385 (95\% CI $=1.0415-1.4727)$. However, in East African countries' context (column (4)), this relative risk decreases for women as compared to men by a factor of $0.8094(95 \% \mathrm{CI}=0.6960-0.9412)$, for individuals in primary education level as compared to those in higher education levels by a factor of 0.3871 (95\% $\mathrm{CI}=0.2411-0.6213)$ and for individuals in the poorest income quintile as compared to those in highest income quintiles by a factor of $0.7775(95 \% \mathrm{CI}=0.6109-0.9894)$; while this risk increases for older people as compared to younger ones by a factor of 1.0288 (95\% CI $=1.0057-1.0523)$. Thus, while in the WAEMU age and income variables have no significant influence on the likelihood of using one mobile money service only, in East Africa it is only the labor force variable that has no significant effect on the likelihood of using one mobile money service only.

In column (2), the relative risk of using two mobile money services in the WAEMU decreases for women as compared to men by a factor of $0.7823(95 \% \mathrm{CI}=0.6372$ 0.9602), for individuals in primary education level as compared to those in higher education levels by a factor of $0.2135(95 \% \mathrm{CI}=0.1292-0.3524)$ and for individuals in the poorest income quintile as compared to those in highest income quintiles by a factor of 0.3994 ( $95 \% \mathrm{CI}=0.2748-0.5802)$; while this risk increases for older people as compared to younger ones by a factor of $1.0721(95 \% \mathrm{CI}=1.0324-1.1132)$ and for individuals in the workforce as compared to those out of the workforce by a factor of 2.0852 $(95 \% \mathrm{CI}=1.6484-2.6378)$. Similarly in the context of East African countries (column (5), this relative risk decreases for women as compared to men by a factor of 0.6692 (95\% CI $=0.5641-0.7939$ ), for individuals in primary education level as compared to those in higher education levels by a factor of $0.2587(95 \% \mathrm{CI}=0.1524-0.4387)$ and for 
individuals in the poorest income quintile as compared to those in highest income quintiles by a factor of 0.3578 ( $95 \% \mathrm{CI}=0.2647-0.4835)$; while this risk increases for older people as compared to younger ones by a factor of $1.0501(95 \% \mathrm{CI}=1.0193-1.0818)$ and for individuals in the workforce as compared to those out of the workforce by a factor of $1.6716(95 \% \mathrm{CI}=1.3460-2.0758)$.

In column (3), the relative risk of using all three mobile money services in the WAEMU decreases for women as compared to men by a factor of $0.4312(95 \% \mathrm{CI}=0.2756-$ 0.6743), for individuals in primary education level as compared to those in higher education levels by a factor of $0.0661(95 \% \mathrm{CI}=0.0315-0.1382)$ and for individuals in the poorest income quintile as compared to those in highest income quintiles by a factor of 0.6813 (95\% CI $=0.3656-1.2695)$; while this risk increases for older people as compared to younger ones by a factor of $1.0973(95 \% \mathrm{CI}=1.0108-1.1910)$ and for individuals in the workforce as compared to those out of the workforce by a factor of 1.8439 (95\% $\mathrm{CI}=1.1686-2.9095)$. Also, in the context of East African countries (column (6), this relative risk decreases for women as compared to men by a factor of 0.6944 (95\% $\mathrm{CI}=0.5565-0.8663$ ), for individuals in primary education level as compared to those in higher education levels by a factor of $0.0801(95 \% \mathrm{CI}=0.0453-0.1415)$ and for individuals in the poorest income quintile as compared to those in highest income quintiles by a factor of $0.1383(95 \% \mathrm{CI}=0.0850-0.2248)$; while this risk increases for older people as compared to younger ones by a factor of $1.0665(95 \% \mathrm{CI}=1.0201-1.1150)$ and for individuals in the workforce as compared to those out of the workforce by a factor of 2.2287 $(95 \% \mathrm{CI}=1.6282-3.0506)$.

Furthermore, while the age and income variables show no significant influence on the likelihood of using one mobile money service only in the WAEMU, it is only the labor force variable that presents no significant influence on this likelihood in the context of East African countries.

\section{Discussion}

The study found that women are less likely to use mobile money accounts as compared to men in both WAEMU and East African countries. This likelihood was observed when it is a question of using one mobile money service among the three services available (sending remittances, receiving remittances, and paying utility bills). This result corroborates the fact that African women commonly turn themselves towards informal financial services instead of using formal financial services (Zins and Weill 2016). Daniels (2014) states that the lower access of women to finance in Africa is due to the fact they face a wide spectrum of challenges. These include, but are not limited to, lower levels of education and financial literacy, lower-income levels, lack of tangible assets or collateral, legal constraints, time and mobility constraints, socio-cultural constraints, inter-role conflicts from juggling domestic and professional roles and a lack of market exposure.

Regarding age characteristics, the results showed that, in comparison to younger people, older people are more likely to use two or all three mobile money services in both the WAEMU and East Africa. However, in terms of using only one mobile money service, this outcome is only significant in East African countries' context. Indeed, being among the older people in the WAEMU does not influence the use of only one mobile money service. The greater use of more than one mobile money service by older people 
could corroborate the fact that like in most developing countries, younger people in the WAEMU are generally unemployed and are among the most vulnerable population, thus most of the time they rely on their parents or relatives to send them money. Older people are generally employed and are in the least vulnerable population and will be those who generally transfer funds to younger ones in developing countries. Therefore, the increased use of mobile money accounts with increasing age is because working-age individuals (adults aged between 25 and 64) are generally those who engage in practices that require the possession of an account to receive salaries and various payments.

Considering the income variable, the results indicated that in comparison to more educated people, being among less educated people is associated with a reduction in the likelihood of using mobile money services in both the WAEMU and East Africa. This outcome was observed in the context of all alternatives of using mobile money services (either the use of one mobile money service only or the use of two mobile money services or the use of all three mobile money services). The greater use of mobile money services by more educated individuals could be explained by the fact that mobile money operations as performed through mobile phones require the capacity to read about transfers and balances in accounts. Less educated people, therefore, may be unable to handle mobile money accounts by themselves through mobile phones (in terms of sending remittances or paying bills) as this requires a process that is different from the common way of using mobile phones for making calls.

The results revealed that, in comparison to richer people, poorer people are less likely to use mobile money accounts in both the WAEMU and East Africa. But, while in the context of East African countries, all the modalities of financial inclusion through mobile money were statistically significant, in the context of WAEMU, only the outcomes of using two mobile money services and three mobile money services were statistically significant. The greater use of mobile money accounts by richer people could be explained by the fact that an active mobile money account requires regularity in terms of the movement of funds. Thus, mobile money accounts are generally more active when held by individuals in the highest income quintiles.

Concerning the labor force variable, the results showed that compared to individuals out of the workforce, individuals in the workforce are more likely to use mobile money services in both WAEMU and East African countries. But, in East African countries, this outcome is not statistically significant in the situation of using only one mobile money service. The greater use of mobile money accounts by individuals in the workforce could 
be as a result of a broad definition of this category to include employees, those who are self-employed as well as those that are seeking employment. Additionally, individuals in the workforce who receive wages from an employer are likely to be paid through a mobile money account.

From the above, it follows that while the age and income variables show no significant influence on the likelihood of using only one mobile money service in the WAEMU, it is the labor force variable that presents no significant influence on this likelihood in East African countries. As for the different modalities of using mobile money services, we find that individuals typically use more than one mobile money service. These outcomes may suggest that in WAEMU countries, individuals who use mobile money the least are unlikely to be older and richer, while in East African countries, individuals who do not use mobile money extensively are unlikely to be in the workforce.

To summarize, the adoption and use of mobile money in both the WAEMU and East African countries are driven by determinants related to the least vulnerable social categories, that is, being male, older, more educated, richer and part of the workforce. The same determinants have been found by Zins and Weill (2016) in Africa and by Senou et al. (2019) in WAEMU countries. The gap observed in terms of average penetration rates of mobile money accounts between the two regions and which has been observed to be in favor of East African countries may be explained by insufficient awareness policies on the attractiveness of mobile financial services in WAEMU countries. For example the current regulatory framework for providing payment services in the WAEMU requires some form of intermediation by banks. This may be limiting room for innovation and making it difficult for new players to compete with banks. It may also be contributing to the increasing costs of mobile payment services due to the fees associated with bank intermediation. In contrast, Kenya (the East African country that is the pioneer of mobile money banking) and other countries that witnessed a rapid growth in the use of mobile payment services have adopted nonbank-led models in line with their levels of national economic and financial sector development. In terms of services and interoperability, most providers in the WAEMU offer basic transfer and bill-payment services, while other services, such as cross-border transaction, mobile loan disbursements and microinsurance, are still less developed than they are in East African benchmark countries like Kenya and Tanzania (see Awad and Newiak, 2016).

\section{Conclusion}

Having started mobile money banking at the same period as many East African countries, a comparison between WAEMU and East African countries based on data drawn from the 2017 World Bank's Global Findex database shows that the average penetration rate of mobile money accounts in East Africa is higher than that of the WAEMU. This study attempted to understand the factors driving the adoption and use of mobile money services in WAEMU countries as compared to East Africa. Using micro-level data from the 2017 Global Findex database, the results revealed that the adoption and use of mobile money accounts are driven by the same determinants in both groups of countries, that is, being male, older, more educated, and richer and part of the workforce. Thus, a greater use of mobile money accounts in both groups of countries is associated with the least vulnerable social categories. Therefore, as the slower rate of penetration 
of mobile money accounts in the WAEMU (compared to East Africa) has nothing to do with the factors determining the adoption and use of mobile money services, it could be attributed to insufficient awareness policies regarding the attractiveness of mobile financial services.

The results of the study imply that national financial inclusion strategies hardly reach the most vulnerable segments (i.e., women, younger, poorer and less educated people and individuals out of workforce) of the population in both the WAEMU and in East Africa. Therefore, more efforts are needed in both regions to put in place strategies that are essential to integrate the most vulnerable segments of the population in the financial sector, particularly regarding mobile financial services.

From the findings of this study, to encourage an increase in the level of financial inclusion through mobile money in the WAEMU, people aged between 25 and 64 (the working-age population) should be more sensitized about the use of mobile money accounts. Such an action could be done through financial literacy programs. Action should be taken to raise the level of individual income. This could be done by an increase in the minimum wage of the countries. Policies aimed at increasing education levels through the introduction of incentives in education systems should be implemented. In this regard, awareness programs on the benefits of good education and the provision of education bursaries must be explored.

This study has an important limitation to the extent that it doesn't include certain key variables such as the marital status, the place of residence, and the employment status. The micro-level data of these variables are not available in the Global Findex database. To better understand the difference in the penetration rates of mobile money accounts between the WAEMU and East Africa, further study could use a broader set of individual level variables by exploiting other databases. Also, further study could exploit the aggregate data from the three Global Findex surveys (2011; 2014 and 2017) using a pseudo-panel method with country fixed effects.

\section{Appendix}

See Tables 3, 4, 5, 6, 7 and 8 . 
Table 3 Descriptive statistics of financial inclusion measures. Source: Author's calculations

\begin{tabular}{|c|c|c|c|c|}
\hline Financial inclusion variables & WAEMU countries & & East African countries & \\
\hline $\begin{array}{l}\text { The ownership of mobile money } \\
\text { account }\end{array}$ & Observation & Mean & Observation & Mean \\
\hline Mobile money account & 7000 & 0.2867 & 11,000 & 0.3289 \\
\hline $\begin{array}{l}\text { The use of mobile money services } \\
\text { (A categorical variables including } \\
\text { the four following modalities) }\end{array}$ & Observation & Mean & Observation & Mean \\
\hline $\begin{array}{l}\text { 1. Using no mobile money service } \\
\text { (reference category) }\end{array}$ & 3902 & 0.4108 & 6538 & 0.4287 \\
\hline $\begin{array}{l}\text { 2. Using one mobile money } \\
\text { service only }\end{array}$ & 3902 & 0.3603 & 6538 & 0.2764 \\
\hline Sending remittances & & 0.1481 & & 0.0971 \\
\hline Receiving remittances & & 0.1873 & & 0.1323 \\
\hline Paying utility bills & & 0.1468 & & 0.1478 \\
\hline $\begin{array}{l}\text { 3. Using two mobile money } \\
\text { services }\end{array}$ & 3902 & 0.1902 & 6538 & 0.2027 \\
\hline $\begin{array}{l}\text { Sending and receiving remit- } \\
\text { tances }\end{array}$ & & 0.0249 & & 0.0470 \\
\hline $\begin{array}{l}\text { Sending remittances and paying } \\
\text { utility bills }\end{array}$ & & 0.0287 & & 0.0312 \\
\hline $\begin{array}{l}\text { Receiving remittances and paying } \\
\text { utility bills }\end{array}$ & & 0.0146 & & 0.0237 \\
\hline $\begin{array}{l}\text { 4. Using all three mobile money } \\
\text { services }\end{array}$ & 3902 & 0.0387 & 6538 & 0.0922 \\
\hline $\begin{array}{l}\text { Sending-receiving remittances } \\
\text { and paying utility bills }\end{array}$ & & 0.0387 & & 0.0922 \\
\hline
\end{tabular}

Data used to perform these calculations are from the 2017 Global Findex database. The sample of WAEMU countries includes Benin, Burkina Faso, Côte d'Ivoire, Mali, Niger, Senegal and Togo. The sample of East African countries includes Ethiopia, Kenya, Madagascar, Malawi, Mauritius, Mozambique, Rwanda, Tanzania, Uganda, Zambia and Zimbabwe

Table 4 Descriptive statistics of the explanatory variables. Source: Author's calculations

\begin{tabular}{|c|c|c|c|c|c|c|}
\hline \multirow{2}{*}{$\begin{array}{l}\text { Samples } \\
\text { Variables }\end{array}$} & \multicolumn{3}{|c|}{ WAEMU countries } & \multicolumn{3}{|c|}{ East African countries } \\
\hline & Observation & Mean & SD & Observation & Mean & SD \\
\hline Female & 7000 & 0.4146 & 0.4927 & 11,000 & 0.5763 & 0.4942 \\
\hline Age & 6941 & 32.6960 & 14.1012 & 10,959 & 34.9380 & 15.5313 \\
\hline Age squared & 6941 & $1,267.8440$ & $1,157.8110$ & 10,959 & $1,461.8590$ & $1,354.1630$ \\
\hline Primary education & 6936 & 0.6091 & 0.4880 & 10,983 & 0.5503 & 0.4975 \\
\hline Secondary education & 6936 & 0.3638 & 0.4811 & 10,983 & 0.4150 & 0.4927 \\
\hline Tertiary education & 6936 & 0.0271 & 0.1624 & 10,983 & 0.0348 & 0.1832 \\
\hline Income: richest 20\% & 7000 & 0.2790 & 0.4485 & 11,000 & 0.2621 & 0.4398 \\
\hline Income: fourth 20\% & 7000 & 0.2119 & 0.4087 & 11,000 & 0.2123 & 0.4089 \\
\hline Income: middle 20\% & 7000 & 0.1840 & 0.3875 & 11,000 & 0.1833 & 0.3869 \\
\hline Income: second 20\% & 7000 & 0.1674 & 0.3734 & 11,000 & 0.1752 & 0.3801 \\
\hline Income: poorest 20\% & 7000 & 0.1577 & 0.3645 & 11,000 & 0.1672 & 0.3732 \\
\hline $\begin{array}{l}\text { Individuals in work- } \\
\text { force }\end{array}$ & 7000 & 0.6773 & 0.4675 & 11,000 & 0.7519 & 0.4319 \\
\hline $\begin{array}{l}\text { Individuals out of } \\
\text { workforce }\end{array}$ & 7000 & 0.3227 & 0.4675 & 11,000 & 0.2481 & 0.4319 \\
\hline
\end{tabular}

Data used to perform these calculations are from the 2017 Global Findex database. WAEMU countries included in the sample are Benin, Burkina Faso, Côte d'Ivoire, Mali, Niger, Senegal and Togo. East African countries in the study are Ethiopia, Kenya, Madagascar, Malawi, Mauritius, Mozambique, Rwanda, Tanzania, Uganda, Zambia and Zimbabwe 
Table 5 Measurement and expected sign of explanatory variables on financial inclusion measures. Source: Author's representation

\begin{tabular}{|c|c|c|}
\hline Variables & Measurement & $\begin{array}{l}\text { Hypothesized } \\
\text { / expected } \\
\text { coefficient }\end{array}$ \\
\hline Female & $\begin{array}{l}\text { Dummy that takes the value } 1 \text { if the respondent is female and } 0 \\
\text { otherwise }\end{array}$ & - \\
\hline Age & Age of the respondent in years & + \\
\hline Age squared & Age of the respondent in years, squared & - \\
\hline Primary education & $\begin{array}{l}\text { Dummy that takes the value } 1 \text { if the respondent completed elemen- } \\
\text { tary education or less (up to } 8 \text { years of education) and } 0 \text { otherwise }\end{array}$ & - \\
\hline Secondary education & $\begin{array}{l}\text { Dummy that takes the value } 1 \text { if the respondent completed second- } \\
\text { ary education and some education beyond secondary education } \\
\text { ( } 9-15 \text { years of education) and } 0 \text { otherwise }\end{array}$ & + \\
\hline Tertiary education & $\begin{array}{l}\text { Dummy that takes the value } 1 \text { if the respondent completed four years } \\
\text { of education beyond high school and/or received a 4-year college } \\
\text { degree and } 0 \text { otherwise }\end{array}$ & + \\
\hline Income: richest 20\% & $\begin{array}{l}\text { Dummy that takes the value } 1 \text { if the respondent falls in the highest } \\
\text { income quintile and } 0 \text { otherwise. Income quintiles are based on the } \\
\text { incomes of the respondents in a country }\end{array}$ & + \\
\hline Income: fourth $20 \%$ & $\begin{array}{l}\text { Dummy that takes the value } 1 \text { if the respondent falls in the second } \\
\text { highest income quintile and } 0 \text { otherwise. Income quintiles are } \\
\text { based on the incomes of the respondents in a country }\end{array}$ & + \\
\hline Income: middle $20 \%$ & $\begin{array}{l}\text { Dummy that takes the value } 1 \text { if the respondent falls in the middle } \\
\text { income quintile and } 0 \text { otherwise. Income quintiles are based on the } \\
\text { incomes of the respondents in a country }\end{array}$ & + \\
\hline Income: second $20 \%$ & $\begin{array}{l}\text { Dummy that takes the value } 1 \text { if the respondent falls in the second } \\
\text { lowest income quintile and } 0 \text { otherwise. Income quintiles are based } \\
\text { on the incomes of the respondents in a country }\end{array}$ & - \\
\hline Income: poorest 20\% & $\begin{array}{l}\text { Dummy that takes the value } 1 \text { if the respondent falls in the lowest } \\
\text { income quintile and } 0 \text { otherwise. Income quintiles are based on the } \\
\text { incomes of the respondents in a country }\end{array}$ & - \\
\hline $\begin{array}{l}\text { Individuals in work- } \\
\text { force }\end{array}$ & $\begin{array}{l}\text { Dummy equal to } 1 \text { if the respondent is in the workforce and } 0 \\
\text { otherwise }\end{array}$ & + \\
\hline $\begin{array}{l}\text { Individuals out of } \\
\text { workforce }\end{array}$ & $\begin{array}{l}\text { Dummy equal to } 1 \text { if the respondent is out of the workforce and } 0 \\
\text { otherwise }\end{array}$ & - \\
\hline
\end{tabular}


Table 6 Mobile money account penetration rates by individual characteristics. Source: Author's calculations

\begin{tabular}{lcc}
\hline Samples & WAEMU countries & East African countries \\
\hline Ownership of accounts & & \\
Yes & $28.6700 \%$ & $32.8900 \%$ \\
No & $71.3300 \%$ & $67.1100 \%$ \\
Gender of respondent & & \\
Male & $68.2600 \%$ & $49.2300 \%$ \\
Female & $31.7400 \%$ & $50.7700 \%$ \\
Respondent's level of education & & \\
Primary & $42.8100 \%$ & $35.3400 \%$ \\
Secondary & $52.0300 \%$ & $59.4600 \%$ \\
Tertiary & $5.1600 \%$ & $5.2000 \%$ \\
Income quintiles & & \\
Richest 20\% & $37.4200 \%$ & $36.8400 \%$ \\
Fourth 20\% & $21.5700 \%$ & $22.6400 \%$ \\
Middle 20\% & $16.5900 \%$ & $16.4500 \%$ \\
Second 20\% & $14.4000 \%$ & $14.3400 \%$ \\
Poorest 20\% & $10.0100 \%$ & $9.7300 \%$ \\
Age of the respondent & & \\
15-24 & $29.1100 \%$ & $31.8300 \%$ \\
25-64 & $68.8800 \%$ & $65.5700 \%$ \\
$65-95$ & $2.0000 \%$ & $2.6000 \%$ \\
Workforce & & \\
Out of workforce & $21.6200 \%$ & $16.8300 \%$ \\
In workforce & $78.3800 \%$ & $83.1700 \%$ \\
\hline Data & & \\
\hline
\end{tabular}

Data used to perform these calculations are from the 2017 Global Findex Database. WAEMU countries included in the sample are Benin, Burkina Faso, Côte d'Ivoire, Mali, Niger, Senegal and Togo. East African countries in the study are Ethiopia, Kenya, Madagascar, Malawi, Mauritius, Mozambique, Rwanda, Tanzania, Uganda, Zambia and Zimbabwe

Table 7 Results of McFadden-Hausman IIA test / WAEMU Countries' sample. Source: Author's computation

$$
\begin{array}{lll}
\text { Coefficients in Eq. } 1 \text { of } & \text { Coefficients in Eq. } 2 \text { of } & \text { Coefficients in Eq. } 3 \text { of } \\
\text { M1=Coefficients in Eq. } 1 \text { of M2 } & M 1=\text { Coefficients in Eq. } 2 \text { of M2 } & \begin{array}{l}
M 1=\text { Coefficients in Eq. } 3 \\
\text { of M2 }
\end{array}
\end{array}
$$

M1 versus $M 2$ without alternative 1

$\begin{array}{lll}\text { Chi } 2 & 1.6800 & 2.6800 \\ \text { Prob }>\text { chi2 } & 0.9998 & 0.9974\end{array}$

$M 1$ versus $M 2$ without alternative 2

$\begin{array}{lll}\text { Chi } 2 & 0.2700 & 1.3300\end{array}$

$\begin{array}{ll}\text { Prob }>\text { chi2 } 1.0000 & 0.9999\end{array}$

M1 versus $M 2$ without alternative 3

Chi $2 \quad 0.2200 \quad 0.7700$

Prob >chi2 $\quad 1.0000$

According to the McFadden-Hausman specification of the test for IIA, the coefficients of the equations $\mathrm{m} 1$ and $\mathrm{m} 2$ should be equal. Throughout the table the $x 2$ probabilities show strong evidence that we cannot reject the null hypothesis. Therefore, the IIA assumption is not violated. $M 1=$ The full specified model. $M 2=$ The model specified excluding one alternative of choice. Alternative $1=$ Using one mobile money service only (Sending remittances or Receiving remittances or Paying utility bills), Alternative $2=$ Using two mobile money services (Sending and receiving remittances or Sending remittances and paying utility bills or Receiving remittances and paying utility bills), Alternative $3=$ Using all three mobile money services (Sending and receiving remittances and paying utility bills). (The base category is "performing no mobile money service") 
Table 8 Results of McFadden-Hausman IIA test / East African Countries' sample. Source: Author's computation

$\begin{array}{lll}\text { Coefficients in Eq. } 1 \text { of } & \text { Coefficients in Eq. } 2 \text { of } & \text { Coefficients in Eq. } 3 \text { of } \\ M 1=\text { Coefficients in Eq. } 1 \text { of M2 } & M 1=\text { Coefficients in Eq. } 2 \text { of M2 } \begin{array}{l}M 1=\text { Coefficients in Eq. } 3 \\ \text { of M2 }\end{array}\end{array}$

M1 versus $M 2$ without alternative 1

$\begin{array}{lll}\text { Chi } 2 & 0.7200 & 1.3800 \\ \text { Prob }>\text { chi2 } & 1.0000 & 0.9999\end{array}$

M1 versus $M 2$ without alternative 2

$\begin{array}{lll}\text { Chi } 2 & 0.8100 & 4.6200\end{array}$

$\begin{array}{lll}\text { Prob >chi2 } 1.0000 & 0.9694\end{array}$

M1 versus $M 2$ without alternative 3

Chi $2 \quad 0.3600 \quad 0.8600$

Prob > chi2 $\quad 1.0000$

According to the McFadden-Hausman specification of the test for IIA, the coefficients of the equations $\mathrm{m} 1$ and $\mathrm{m} 2$ should be equal. Throughout the table the $\times 2$ probabilities show strong evidence that we cannot reject the null hypothesis. Therefore, the IIA assumption is not violated. $M 1=$ The full specified model. $M 2=$ The model specified excluding one alternative of choice. Alternative $1=$ Using one mobile money service only (Sending remittances or Receiving remittances or Paying utility bills), Alternative $2=$ Using two mobile money services (Sending and receiving remittances or Sending remittances and paying utility bills or Receiving remittances and paying utility bills), Alternative $3=$ Using all three mobile money services (Sending and receiving remittances and paying utility bills). (The base category is "performing no mobile money service")

\section{Abbreviations}

AHP: Analytical hierarchy process; ATM: Automated teller machines; CBWAS: Central Bank of West African States; Cl: Confidence interval; IIA: Independence of irrelevant alternatives; LR: Likelihood ratios; LSGDM: Large-scale group decisionmaking; M-PESA: M for "mobile", PESA for "money" in Kiswahili; RIA: Research ICT Africa; RRR: Relative risk ratio; SEM: Structural equation modelling; TAM: Technology acceptance model; UNSD: United Nations Statistics Division; UTAUT: Unified theory of acceptance and use of technology; WAEMU: West African economic and monetary union.

\section{Acknowledgements}

I am grateful to the African Economic Research Consortium (Grant No. RT 16514) for providing funds to carry out this study. I am also grateful to my resource person and the other resource persons (members of African Economic Research Consortium's thematic group C), for their constructive comments on the earlier versions of this paper. I thank participants at the African Department Visiting Scholar Seminar at the International Monetary Fund, Washington D.C., USA, April 11, 2018 for their useful comments and suggestions. I am indebted to the editor and the anonymous reviewers for their valuable comments and suggestions that greatly improved the paper.

\section{Authors' contributions}

Not applicable.

Funding

This study received a grant from the AERC (African Economic Research Consortium). The funding received from AERC covered all the steps of this research from the research proposal stage to the final report stage.

\section{Availability of data and materials}

The data used in this study are collected from the World Bank's 2017 Global Financial Inclusion (Global Findex) Database (World Bank Group. Washington, D.C. http://www.worldbank.org/globalfindex).

\section{Declaration}

\section{Competing interests}

The author declares that he has no competing interests.

Received: 9 January 2020 Accepted: 25 March 2021

Published online: 12 April 2021

\section{References}

Afawubo K, Couchoro MK, Agbaglah M, Gbandi T (2020) Mobile money adoption and households' vulnerability to shocks: Evidence from Togo. Appl Econ 52(10):1141-1162. https://doi.org/10.1080/00036846.2019.1659496

Akinyemi BE, Mushunje A (2020) Determinants of mobile money technology adoption in rural areas of Africa. Cog Soc Sci 10(1080/23311886):1815963

Allen F, Demirguc-Kunt A, Klapper L, Martinez-Peria MS (2016) The foundations of financial inclusion: Understanding ownership and use of formal accounts. J Financ Intermed 27:1-30 
Aron J (2017) Leapfrogging: A survey of the nature and economic implications of mobile money. CSAE Working Paper Series 2017-02. Centre for the Study of African Economies, University of Oxford.

Aron J (2018) Mobile money and the economy: a review of the evidence. World Bank Res Obs 33(2):135-188

Awad R, Newiak M (2016) Mobile banking. In: Kireyev AP (ed) Building integrated economies in West Africa: lessons in managing growth, inclusiveness, and volatility. International Monetary Fund, 2016, Washington, DC, pp 309-316.

Bair S, Tritah A (2019) Mobile money and inter-household financial flows: evidence from madagascar. Rev Écon 70(5):847-872

Banque de France (2014) La politique et les agrégats monétaires dans les zones d'émission africaines: Les enjeux de I'inclusion financière en Zone franc. Rapport Annuel de la Zone Franc 2014:107-111

Daniels N (2014) Women's financial inclusion in Africa: barriers, costs and opportunities. BUWA! J Afr Women's Exp, December, 35-39.

Demirguc-Kunt A, Klapper L, Singer D, Oudheusden PV (2015) The Global Findex Database 2014: measuring financial inclusion around the world. Policy Research Working Paper No. 7255. The World Bank, Washington, DC

Demirgüç-Kunt A, Klapper L, Singer D, Ansar S, Hess J (2018) The Global Findex Database 2017: measuring financial inclusion and the fintech revolution. World Bank, Washington, DC. https://doi.org/10.1596/978-1-4648-1259-0

Global Financial Inclusion (Global Findex) Database (2017) World Bank Group, Washington, D.C. http://www.worldbank. org/globalfindex. Accessed 12 Jan 2020.

Greene HW (ed) (2012) Econometric analysis. Pearson Education, England

Gujarati D (2011) Econometrics by example. Palgrave Macmillan, New York

Hausman JA, McFadden DL (1984) Specification tests for the multinomial logit model. Econometrica 52:1219-1240

Jafarov E, Maino R, Pani M (2020) Financial Repression is Knocking at the Door, Again. Should We Be Concerned? IMF Working Paper WP/19/211.

Lema A (2017) Factors influencing the adoption of mobile financial services in the unbanked population. J Hum Soc Sci 9:37-51

Leyshon A, Thrift N (1993) The restructuring of the U.K. financial services industry in the 1990s: a reversal of fortune? J Rur Stud 9(3):223-241

Malinga RB, Maiga G (2019) A model for mobile money services adoption by traders in Uganda. The elect J Inform Syst Develop Count. https://doi.org/10.1002/isd2.12117

McKinnon RI (1973) Money and capital in economic development. The Brookings Institute, Washington, D.C.

Murendo C, Wollni M, de Brauw A, Mugabi N (2018) Social network effects on mobile money adoption in Uganda. J Dev Stud 54(2):327-342

Peruta MD (2018) Adoption of mobile money and financial inclusion: a macroeconomic approach through cluster analysis. Econ Innov New Tech 27(2):154-173. https://doi.org/10.1080/10438599.2017.1322234

Senou MM, Ouattara W, Houensou DA (2019) Is there a bottleneck for mobile money adoption in WAEMU. Trans Corporations Rev 11(2):143-156. https://doi.org/10.1080/19186444.2019.1641393

Shaw E (1973) Financial deepening in economic development. Oxford University Press, New York

UNSD (2021) Statistics Division: Methodology. https://unstats.un.org/unsd/methodology/m49/. Accessed 16 Feb 2021.

Zins A, Weill L (2016) The determinants of financial inclusion in Africa. Rev Dev Financ 6(1):46-57

\section{Publisher's Note}

Springer Nature remains neutral with regard to jurisdictional claims in published maps and institutional affiliations.

\section{Submit your manuscript to a SpringerOpen ${ }^{\circ}$ journal and benefit from:}

- Convenient online submission

- Rigorous peer review

- Open access: articles freely available online

- High visibility within the field

- Retaining the copyright to your article

Submit your next manuscript at $\boldsymbol{\Delta}$ springeropen.com 